\title{
Epidemiological Aspects of Diseases Seen in Pediatric Surgery Consultation at the Kara Teaching Hospital
}

\author{
Missoki Azanlédji Boume ${ }^{1 *}$, Kwami Edem Edoh Bikor², Ouro-Bagna Tchagbele ${ }^{3}$, \\ Kokou Agbekogni Réné Ségbedji ${ }^{3}$, Komi Deladem Azoumah³, \\ Gamédzi Komlatsè Akakpo-Numado²
}

${ }^{1}$ Pediatric Surgery Department in Kara Teaching Hospital, Kara, Togo

${ }^{2}$ Pediatric Surgery Department in Campus Teaching Hospital, Lomé, Togo

${ }^{3}$ Pediatric Department in Kara Teaching Hospital, Kara, Togo

Email: ^bmissoki@yahoo.fr, ^missokiboume@gmail.com

How to cite this paper: Boume, M.A., Bikor, K.E.E., Tchagbele, O.-B., Ségbedji, K.A.R., Azoumah, K.D. and Akakpo-Numado, G.K. (2021) Epidemiological Aspects of Diseases Seen in Pediatric Surgery Consultation at the Kara Teaching Hospital. Open Journal of Pediatrics, 11, 646-655.

https://doi.org/10.4236/ojped.2021.114060

Received: October 16, 2021

Accepted: November 23, 2021

Published: November 26, 2021

Copyright $\odot 2021$ by author(s) and Scientific Research Publishing Inc. This work is licensed under the Creative Commons Attribution International License (CC BY 4.0).

http://creativecommons.org/licenses/by/4.0/

(c) (i) Open Access

\begin{abstract}
Background: Pediatric surgery in developing countries faces serious problems of inadequate infrastructures and equipment. Since July 2019, a new department was created in the north of Togo. It is in this context that this study is initiated, with the aim of taking stock of the epidemiological distribution of pediatric surgical diseases. Material and methods: This was a retrospective and descriptive study over a period of eighteen months, from October 30, 2019 to April 30, 2021. It took place in the pediatric surgery department of the Kara teaching hospital. It concerns pathologies seen at the consultation in the department collected in consultation register. Epidemiological parameters were studied. Results: In eighteen (18) months, two hundred and fifty-nine children, were seen in pediatric surgery consultation at the Kara Teaching Hospital. The annual frequency of consultations was 172.66 . The monthly frequency was 14.39 . The average age of the children was 4.56 years with extremes of 2 days and 15 years. There were 194 boys (74.90\%) and 65 girls $(25.10 \%)$. At the consultation, whatever the reason, the examination was normal in 17 children and 242 children had abnormalities. Two hundred and twelve children (81.85\%) had each one abnormality and 30 children (11.58\%) had each at least two. A total of 298 diseases were reported in the 242 children. These were 218 congenital diseases $(73.15 \%)$ dominated by urological abnormalities with $37.16 \%$ of cases and 80 acquired diseases (26.85\%). Acquired diseases were for $26.85 \%$ and dominated by limb trauma and infectious pathologies including chronic osteomyelitis. Conclusion: Pathologies seen in pediatric surgery consultation were dominated by congenital diseases.
\end{abstract}


Urological malformations are the most represented. This study forms a basis for other more extensive ones.

\section{Keywords}

Pediatric Surgery, Congenital Malformation, Children

\section{Introduction}

The first pediatric surgery department was created in Togo in 1987. Until 2015, this department was the only one in the country before campus one was created [1]. Despite this, access to pediatric surgical health care for populations in the north of the country was increasingly difficult. Thus, in July 2019, a pediatric surgery department was created at the Kara Teaching Hospital in the north of the country [2]. After its creation, the first consultation took place on 30 October 2019.

The pediatric surgery in developing countries such as Togo faces serious problems of inadequate infrastructures and equipment. To put it, Grosfel et al. [3] said that nowhere in the world is the global burden of surgical diseases more evident than in Africa. They declare that in developing countries, paediatric surgery suffers from inadequate infrastructure, financial resources and government support [3]. This situation has recently been aggravated for almost two years by the health crisis of the COVID-19 pandemic. The lack of financial resources, despite sometimes the manifest goodwill of some hospital administrators, forces them to require prioritization of the equipment to be acquired. The prioritization of its equipment, which depends primarily on the nature of pediatric surgical emergencies, also takes into account the epidemiology of pediatric surgical conditions. It is in this context that this study is initiated, with the aim of taking stock of the epidemiological distribution of pediatric surgical diseases.

\section{Material and Methods}

This was a retrospective and descriptive study over a period of eighteen months, from October 30, 2019 to April 30, 2021. It took place in the pediatric surgery department of the Kara teaching hospital. This period corresponds to the first eighteen months of activity of the department. Indeed, after its creation on July 5, 2019 [2], the first consultation took place in the service, on October 30 of the same year. The study focused on cases of children of both sexes, aged 0 to 15 years, reported in the service's consultation register. Only the first consultation was considered for each patient. Consultations take place on Monday afternoons from 3 p.m. and Wednesday mornings from 8 a.m. They are all made by the only pediatric surgeon in the department. Epidemiological parameters were studied. Statistical analyses were done by chi-2 tests $(\mathrm{p}<0.005)$. 


\section{Results}

In eighteen (18) months, two hundred and fifty-nine children were seen in pediatric surgery consultation at the Kara teaching hospital. The annual frequency of consultations was 172.66. The monthly frequency was 14.39. Figure 1 shows the monthly distribution of consultations over the eighteen months.

The average age of the children was 4.56 years with extremes of 2 days and 15 years

There were 194 boys (74.90\%) and 65 girls (25.10\%).

At the consultation, whatever the reason, the examination was normal in 17 children and 242 children had abnormalities. Two hundred and twelve children (81.85\%) had each one abnormality and 30 children $(11.58 \%)$ had each at least two. A total of 298 diseases were reported in the 242 children. These were 218 congenital diseases (73.15\%) and 80 acquired diseases (26.85\%). The difference between congenital and acquired diseases conditions at consultation is statistically significant with $\mathrm{p}=0.0041$. Table 1 shows the distribution of congenital diseases according to the regions or systems concerned.

Head and neck malformations $(n=15)$ : They were composed mainly of cleft lip in 8 cases $(53.33 \%)$, followed by fibromatosis Colli in 2 cases (13.33\%). The other ailments which were gill fistula, right eyebrow leptomeninges cyst, sublingual cyst, supernumerary ear and tongue frenulum were each depicted once.

Limb malformations $(n=55)$ : They were dominated by knee deviations in 27 cases $(49.09 \%)$, followed by hand and foot malformations in 20 cases (36.36\%). Congenital radioulnar synostosis (Figure 2) came in third place with 2 cases (3.67\%) followed by tibial aplasia (Figure 3) with also 2 cases (3.67\%).

Other congenital anomalies such as hypoplasia of the femur, unequal length of the lower limbs, generalized achondroplasia and congenital elbow flexum were each represented by 1 case $(1.89 \%)$.

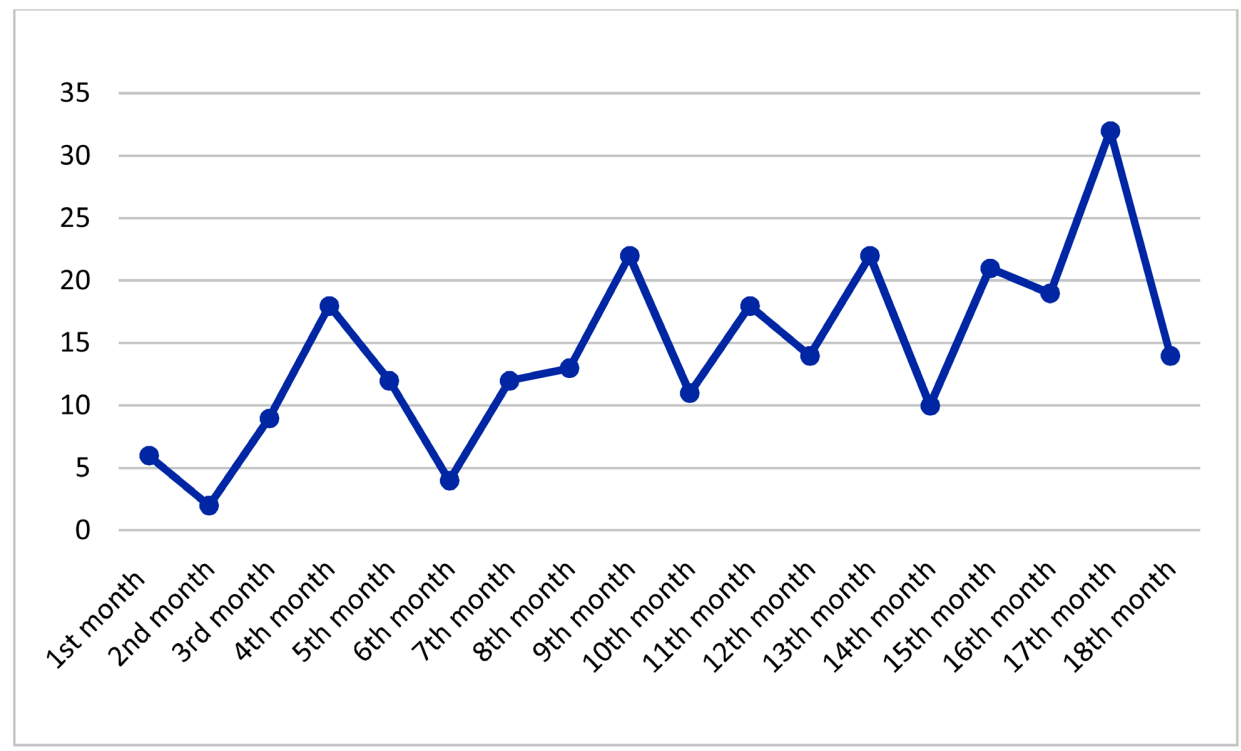

Figure 1. Distribution of consultation staff by 18 months of the study period. 
Table 1. Distribution of congenital diseases by region or system concerned.

\begin{tabular}{ccc}
\hline & $\boldsymbol{n}$ & $\%$ \\
\hline Urological malformations & 81 & 37.15 \\
Limbs malformations & 55 & 25.23 \\
Abdominal wall malformations & 53 & 24.31 \\
Head and neck malformations & 15 & 6.88 \\
Malformations of the digestive system & 9 & 4.13 \\
Vascular malformations & 3 & 1.38 \\
Chest malformations & 1 & 0.46 \\
Spinal malformations and central nervous system & 1 & 0.46 \\
Total & 218 & 100.00 \\
\hline
\end{tabular}

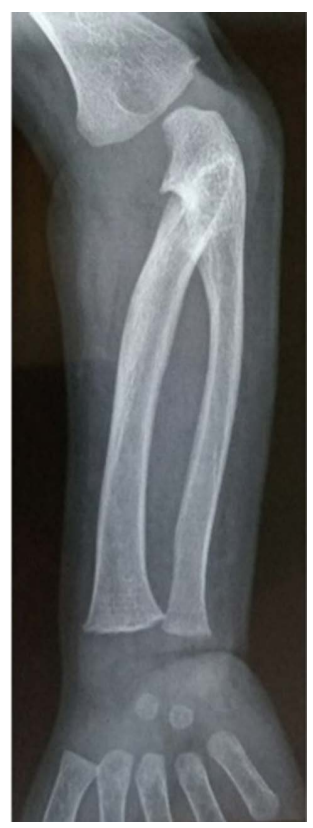

Figure 2. Congenital proximal radioulnar synostosis in a 7-year-old boy.

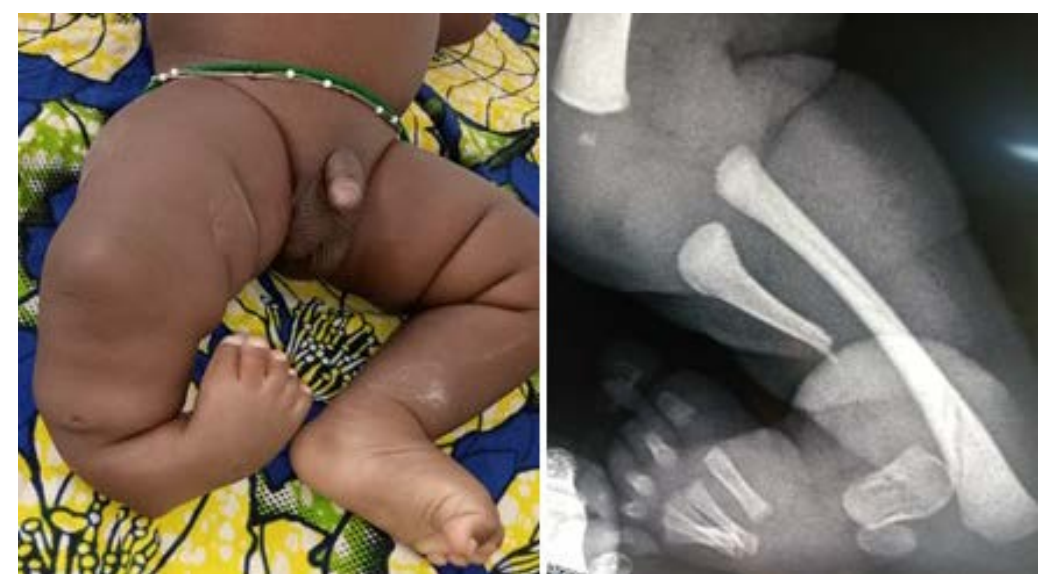

Figure 3. Type IIb tibial aplasia in a 6-month-old infant. 
Knee deviations were a knee recurvatum in 11 cases, a valgum knee in 14 cases and a varum knee in 2 cases.

Urological malformations $(n=81)$ : Abnormalities of the peritoneovaginal canal and Nück's cala were the most represented with 48 cases (59.26\%), followed by testicular descent abnormalities with 19 cases $(23.47 \%)$. Hypospadias ranked third with 7 cases $(8.64 \%)$ before renal multicystic dysplasia with 2 cases $(2.47 \%)$. The valves of the posterior urethra, the ectopic mouthing of the ureter, the micropenis, the epididymal cyst and the small congenital bladder were each represented once.

Malformations of the digestive system $(n=9)$ : They were divided between anorectal malformations with 2 cases (22.22\%) and Hirschsprung's disease with 7 cases $(77.77 \%)$. Figure 4 shows a nine-year-old boy seen for chronic constipation in Hirschsprung's disease.

Abdominal wall malformations $(n=53)$ : These were only umbilical hernias in the 53 cases $(100 \%)$.

Other malformations ( $n=5$ ): 2 cases of subcutaneous hemangioma and 1 case for Poland syndrome, spina bifida and cystic lymphangioma of the neck were noted, respectively. Acquired ailments were also varied. Table 2 shows the distribution of acquired diseases according to the regions or devices concerned.

Limb trauma, infectious diseases and urogenital conditions were the most represented.

Limb trauma $(n=36)$ : These were mostly limb fractures with 18 cases $(50 \%)$, followed by cerebral palsy with 7 cases $(19.44 \%)$. Elongation of the brachial

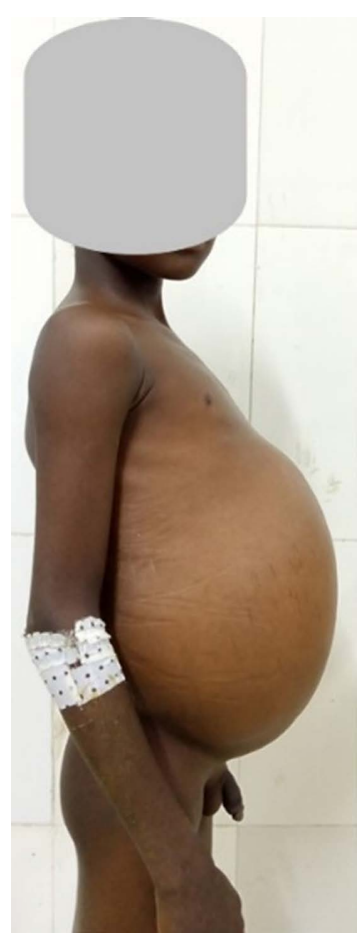

Figure 4. Nine-year-old boy seen for chronic constipation in Hirschsprung's disease (note abdominal bloating). 
Table 2. Distributions of acquired conditions by region or system concerned.

\begin{tabular}{ccc}
\hline & $\mathbf{n}$ & $\%$ \\
\hline Limbs trauma & 36 & 45 \\
Infectious pathologies & 13 & 16.25 \\
Other acquired conditions & 11 & 13.75 \\
Urogenital conditions & 7 & 8.75 \\
Tumor disease & 4 & 5 \\
Burns and their sequelae & 3 & 3.75 \\
Abdominal wall disease & 3 & 3.75 \\
Proctological diseases & 3 & 3.75 \\
Total & 80 & 100 \\
\hline
\end{tabular}

plexus was noted in 3 cases (8.33\%). Withdrawals of the quadriceps from intramuscular injections and muscle bruises were found in 2 cases (5.55\%) each.

Infectious pathologies $(n=13)$ : Chronic osteomyelitis was in the lead with 5 cases $(38.46 \%)$, followed by abscesses of soft parts with 4 cases $(30.77 \%)$. The other pathologies were a low urinary tract infection in 2 cases $(15.38 \%)$, a toe infection in 1 case (7.69\%) and purulent pleurisy in 1 case (7.69\%).

Urogenital disorders $(n=7)$ : Coalescence of the labia minora (5; 71.44\%), bladder lithiasis $(1 ; 14.28 \%)$ and urethral fistula $(1 ; 14.28 \%)$ made up this series.

Tumor disorders $(n=4): 1$ case of osteosarcoma of the right tibia and two cases of exostosis were the tumor pathologies seen in consultation.

Burn sequelae ( 3 cases), rectal prolapse ( 3 cases) and postoperative ventrations ( 3 cases) made up the rest of the series of acquired diseases.

\section{Discussion}

For the first time in 2019, a pediatric surgery department was created in the northern region of Togo [2]. He is housed at the Kara teaching hospital, which is the reference hospital in the north of the country. Once the administrative act was taken in July 2019, the first consultation took place on 30 October of the same year. Indeed, the pediatric surgeon who was assigned to it was in practice in Lomé, the capital of the country, located 420 kilometers from the city of Kara. The administration of the Kara teaching hospital was not prepared to welcome a new pediatric surgery department. Thus, when the pediatric surgeon started work in August 2019, he could not have an office. This is what has delayed the start of its activities. He was able to make the first consultation on October 30, 2019. This date was the beginning of the study period in our series. Until 2019, Togo's two pediatric surgery departments were all in the capital Lomé, in the far south of the country. This obviously made access to pediatric surgical care very laborious for the populations of the north of the country. It was therefore important that not only one, but several pediatric surgery departments be created 
due to at least one per economic region in order to facilitate this accessibility.

The practice of pediatric surgery in developing countries such as Togo is facing serious problems of equipment shortages, aggravated for almost two years by the health crisis of the Covid-19 pandemic. The lack of financial resources, despite sometimes the manifest goodwill of some hospital administrators, forces them to ask for a prioritization of the equipment to be acquired. The prioritization of its equipment, which depends primarily on the nature of pediatric surgical emergencies, also takes into account the epidemiology of pediatric surgical diseases. It is in this context that this study is initiated, to allow us to take stock of the proportional frequency of ailments. These data will situate the opinion on not only the frequency but also the nature of the conditions received in the service. From there, we hope that the needs and their prioritization can be more easily motivated in front of certain decision-makers.

This study was limited to diseases received in consultation. This limitation to the consultation register can be considered as a limit to this study, but we found that it showed the great diversity of pediatric surgical pathologies encountered. Even though most of the children seen in the consultation will be hospitalized at some point, to undergo surgical procedures, the extension of a new study to hospitalized patients can give more reliable figures. Indeed, the pathologies admitted in emergency and hospitalized, for the most part, differ well from those received rather in consultation for which surgical management is often scheduled. Whatever it is, the results of this study are now original and will remain references for the pediatric surgery department of the Kara teaching and the northern region of Togo.

The annual frequency of consultations was approximately 173 in our series. It is very low compared to that reported by Gnassingbe et al. [4] in Lomé in 2010. They had reported about 1434 consultations per year. Indeed, their study focused on the first 20 years of surgical activities of the pediatric surgery department of the Tokoin teaching hospital. This is a great period of study more significant than ours. It is not known that it would have been the annual frequency of consultations during the first two years of operation in this service. In addition to the large study period that does not allow comparison with our study, there is also the fact that the pediatric surgery department in which the study was done was the only one in the country at the time. It was therefore in this department that all cases of pediatric surgery were consulted. Since 2015, a second pediatric surgery department has been created at the Campus teaching hospital in Lomé. It had made it possible to reduce the attendance of the first service. Our pediatric surgery department created in 2019 is the $3^{\text {rd }}$ pediatric service in the country. It is closer to the population of the northern half of the country. In this context, the frequency of consultations may have decreased.

The observation of the consultation curve shows an overall increase over the months. It can be inferred from this that, an increase in consultations over time is to be expected. When consultations increase, hospitalizations will also follow. 
However, we do not have child inpatient rooms for pediatric surgery. Since the creation of the service, we have shared the same hospital rooms with general surgeons and adult urologists. In addition to the limited space that limits hospitalizations and activities, there is also the fact that, children who will benefit from scheduled surgery may be forced to wait longer. These findings are one more reason to motivate to put at least the minimum for the proper installation of infrastructure and equipment.

Congenital diseases occupied the first place of the pathologies seen in pediatric surgery consultation. They accounted for $73.15 \%$. They dominate the pathologies treated in pediatric surgical departments and can affect all regions and systems of the body. These are abnormalities of structures and or functions, which are present at birth [5] [6]. They may or may not be clinically visible. They represent one of the major causes of infant and neonatal mortality, especially in severe forms [6] [7] [8]. In the United States of America, they are the major cause of infant mortality. [9]. In India, 10\% - 15\% of newborn deaths are due to congenital diseases [10]. The situation is by no means better in developing countries with high infant mortality rates, related to these malformations [7] [11] [12]. To this end, they represent a real public health problem [5] [7] [8]. The fight to reduce infant mortality from congenital diseases in developed countries has gone through several stages, the main one being the establishment of epidemiological surveillance networks for congenital diseases [9] [13]. Most of these countries have registries of birth defects and potentially teratogenic environmental agents [9]. In most developing countries, such registries are non-existent. Mortality and the incidence of congenital diseases in these countries remain speculative and without any real database. Epidemiological studies have been conducted in Lomé in Togo [4] and Abidjan (Côte d'Ivoire) [7] on congenital diseases, but they have been monocentric. However, they provided a panoramic overview of congenital diseases.

Congenital diseases in our series were dominated by urological abnormalities with $37.16 \%$ of cases. The series of Kouamé et al. [7] was characterized by the predominance of osteoarticular malformations. This predominance was found by Kouamé et al. [7] and by other authors [14]-[19]. Some studies, on the other hand, have noted a predominance of neural tube defects [20] [21] [22]. This difference in distribution could be explained by the unknown or known multifactorial origin of congenital diseases [22]. We also believe that the distribution of abnormalities in groups of congenital diseases is not uniform for all authors. As an example, we did not find in the series of Kouamé et al. [7], the abnormalities of the peritoneovaginal canal while they were classified in the urological malformations of our series.

Our study was not limited to congenital anomalies but to all diseases seen at consultation in pediatric surgery department. Thus, it made us possible to note that acquired diseases were for $26.85 \%$ of consultations. They were dominated by limb trauma and infectious pathologies including chronic osteomyelitis. Less 
noisy than acute osteomyelitis, they are mainly characterized by an inexhaustible fistula that often leads to consultation.

Even limited by the study period, this study forms a basis for other more extensive ones that will encompass cases of consultation and hospitalization or that will be multicenter.

\section{Conclusion}

Pathologies seen in pediatric surgery consultation were dominated by congenital diseases. Urological malformations are the most represented. Even limited by the study period, this study forms a basis for other more extensive ones that will encompass cases of consultation and hospitalization or that will be multicenter.

\section{Ethical Committee Approval}

The authors declare having Ethical committee approval for the study.

\section{Conflicts of Interest}

The authors declare no conflicts of interest regarding the publication of this paper.

\section{References}

[1] Republic of Togo. Order $\mathrm{N}^{\circ} 134 / 2015 / \mathrm{MSPS} / \mathrm{CAB} / \mathrm{SG}$.

[2] Republic of Togo. Order $\mathrm{N}^{\circ} 134 / 2019 / \mathrm{MSHP} / \mathrm{CAB} / \mathrm{SG}$.

[3] Grosfel, J.L. and O'Neill, J.A. (2012) History of Pediatric Surgery: A Brief Overview. In: Coran, A.G., Adzick, N.S., Krummel, T.M., Laberge, J.-M., Shamberger, R.C. and Caldamone, A.A., Eds., Pediatric Surgery, 7th Edition, Elsevier, Philadelphia, $1738 \mathrm{p}$

[4] Gnassingbe, K., Tomta, K., Akakpo-Numado, G.K., Lamboni, D. and Tekou, H. (2010) Clinically Visible Malformations in Children: Epidemiological Aspects and the Problems Posed by Their Management at the CHU-Tokoin in Lomé. Journal de la Recherche Scientifique de P Université de Lomé (Togo), 12, 105-110.

[5] OMS: Malformations congénitales [Internet]. http://apps.who.int/gb/ebwha/pdf_files/WHA63/A63_10-fr.pdf

[6] Kamla, J.I., Kamgaing, N., Nguifo Fongang, E.J., Fondop, J., Billong, S., et al. (2017) Epidemiology of Congenital Malformations Diagnosed at Birth in Yaounde. Health Sciences and Disease, 18, 53-62.

[7] Kouamé, D.B., Brou-N'guetta, A.I., Kouamé, Y.G.S., Sounkéré, M., Koffi, M., Yaokreh, J.B., et al. (2015) Epidemiology of Congenital Abnormalities in West Africa: Results of a Descriptive Study in Teaching Hospitals in Abidjan: Côte d'Ivoire. African Journal of Paediatric Surgery, 12, 51-55. https://doi.org/10.4103/0189-6725.150983

[8] Boyle, B., Addor, M.C., Arriola, L., Barisic, I., Bianchi, F., Csáky-Szunyogh, M., et al. (2018) Estimating Global Burden of Disease Due to Congenital Anomaly: An Analysis of European Data. ADC Fetal \& Neonatal Edition, 103, 22-28. https://doi.org/10.1136/archdischild-2016-311845

[9] Mathews, T.J., Menacker, F., Mac Dorman, M.F. and Mac, D. (2003) Infant Mortality Statistics from the 2001 Period Linked Birth/Infant Death Data Set. National Vi- 
tal Statistics Reports, 52, 1-28. https://doi.org/10.1037/e558952006-001

[10] Sarkar, S., Patra, C., Dasgupta, M.K., Nayek, K. and Karmakar, P.R. (2013) Prevalence of Congenital Anomalies in Neonates and Associated Risk Factors in a Tertiary Care Hospital in Eastern India. Journal of Clinical Neonatology, 2, 131-134. https://doi.org/10.4103/2249-4847.119998

[11] Kouamé, B.D., Dick, R.K., Ouattara, O., Traoré, A., Gouli, J.C. and Roux, C. (2004) Analyses of Prognostic Factors for Omphalocele in Côte d'Ivoire. Medecine d' Afrique Noire, 54, 1-4.

[12] Kumar, A., Agarwala, S., Srinivas, M., Bajpai, M., Bhatnagar, V., Gupta, V.P., et al. (2005) Anorectal Malformations and Their Impact on Survival. Indian Journal of Pediatrics, 72, 1039-1042. https://doi.org/10.1007/BF02724407

[13] Lowry, R.B. (2002) Les anomalies congénitales au Canada: Rapport sur la santé périnatale, Ottawa-Ontario: Santé Canada, $72 \mathrm{p}$.

[14] Sabiri, N., Kabiri, M., Karboubi, L., Bouziane, A. and Barkat, A. (2013) Risk Factors for Congenital Malformations: Prospective Study at the Souissi Maternity Hospital in Rabat, Morocco. Journal de pédiatrie et de puériculture, 26, 198-203. https://doi.org/10.1016/j.jpp.2013.05.001

[15] Kouamé, B.D., N’guessan Brou, I., Koffi, K.A., Odéhouri, T.H., Gouli, J.C., Yenan, J., et al. (2014) Epidemiology of Congenital Anomalies in Hospital Centres. Revue International des Sciences Médicales, 16, 9-16.

[16] Mashako, R.M., Nsibu, N.C., Nkinamubanzi, M., Bitwe, M.R., Kajibwami, E., Masamba, L., et al. (2017) Congenital Malformations in the East of the Democratic Republic of the Congo: Challenges and Prospects. International Journal of Innovation and Scientific Research, 33, 256-261.

[17] Marwah, S., Sharma, S., Kaur, H., Gupta, M. and Goraya, S.P.S. (2014) Surveillance of Congenital Malformations and Their Possible Risk Factors in a Teaching Hospital in Punjab. International Journal of Reproduction, Contraception, Obstetrics and Gynecology, 3, 162-167. https://doi.org/10.5455/2320-1770.ijrcog20140332

[18] Alshehri, M.A. (2005) Pattern of Major Congenital Abnormalities in Southwestern Saudi Arabia. Bahrain Medical Bulletin, 27, 1-6.

[19] Chente N'guefack, C., Egbe, O.T., Halle, E.G., N'zesseu Djomo, A.L., Nana Njamen, T., Tsingaing Kamgaing, J., et al. (2013) Congenital Malformations at the Douala General Hospital: Epidemiological and Clinical Aspects. Journal de la SAGO, 14, 11-16.

[20] Kamgaing, K.E., Rogombe, M.S., Maniaga, K.R., Tsague, G., Minko, J.I., Mi Kama, M.E., et al. (2018) Congenital Malformations Seen in Libreville, Management and Evolution. EC Paediatrics, 7, 422-434.

[21] Gandhi, M.K., Chaudhari, U.R. and Thakor, N. (2016) Incidence and Distribution of Congenital Malformations Clinically Detected at Birth: A Prospective Study at Tertiary Care Hospital. International Journal of Research in Medical Sciences, 4, 1136-1139. https://doi.org/10.18203/2320-6012.ijrms20160797

[22] Mossey, P.A., Little, J., Munger, R.G., Dixon, M.J. and Shaw, W.C. (2009) Cleft Lip and Palate. The Lancet, 374, 1773-1785.

https://doi.org/10.1016/S0140-6736(09)60695-4 